\title{
Evidence of the role of free-living birds as disseminators of Salmonella spp.
}

\section{Evidências das aves de vida livre como transmissoras de Salmonella spp.}

\author{
Antonio Jackson Forte Beleza1 (1) (https://orcid.org/0000-0001-9406-9583) \\ William Cardoso Maciel ${ }^{1 *}$ (D) (https://orcid.org/0000-0002-6093-7933) \\ Elisângela de Souza Lopes ${ }^{2}$ (D) (https://orcid.org/0000-0002-0533-8751) \\ Átilla Holanda de Albuquerque 3 (D) (https://orcid.org/0000-0003-3200-9184) \\ Arianne Silva Carreira' ${ }^{1}$ (D) (https://orcid.org/0000-0002-3215-4560) \\ Carlos Henrique Guedes Nogueira' (D) (https://orcid.org/0000-0001-9941-6740) \\ Jéssica de Melo Bandeira1 (D) (https://orcid.org/0000-0003-2756-1927) \\ Ruben Horn Vasconcelos ${ }^{4}$ (D) (https://orcid.org/0000-0002-6069-0053) \\ Régis Siqueira de Castro Teixeira ${ }^{1}$ (D) (https://orcid.org/0000-0002-8348-7218)
}

\begin{abstract}
This study aimed to review aspects of Salmonella spp. in free-living birds and their potential as disseminators for domestic animals, man, and the environment. Isolation of Salmonella spp. have been reported in several species of wild birds from Passeridae and Fringillidae, among other avian families, captured in countries of North America and Europe, where Salmonella ser. Typhimurium is the most frequently reported serotype. The presence of pathogens, including Salmonella, may be influenced by several factors, such as diet, environment, exposure to antibiotics, infection by pathogenic organisms and migration patterns. Researches with wild birds that live in urbanized environment are important, considering that birds may participate in the transmission of zoonotic pathogens, which are more prevalent in cities due to the human activity. Based on the information collected, this article concludes that wild birds are still important disseminators of pathogens in several geographic regions and may affect man, domestic animals, and other birds.
\end{abstract}

KEYWORDS: salmonellosis; wild birds; zoonosis.
RESUMO: O objetivo deste estudo foi realizar uma revisão acerca da Salmonella spp. em aves de vida livre e o potencial delas como disseminadores para animais domésticos, homem e meio ambiente. Casos na literatura relatando Salmonella spp. têm sido descritos em diversas espécies de aves silvestres da família Passeridae e Fringilidae em países da América do Norte e Europa, sendo Salmonella ser. Typhimurium o sorotipo relatado mais frequentemente. A presença de patógenos como Salmonella spp. pode ser influenciada por fatores como dieta, ambiente onde vive, contaminação por antibióticos, infecção por organismos patogênicos e padróes de migração. Pesquisas envolvendo as aves silvestres que vivem em ambiente urbanizado sáo importantes, pois as aves podem possibilitar a transmissão de patógenos zoonóticos que têm maior prevalência em áreas urbanas devido a mecanismos de ação humana. Com base nas informaçôes coletadas, conclui-se que as aves silvestres continuam sendo importantes na disseminação de patógenos em diversas regióes geográficas, podendo afetar o homem, animais domésticos e outras aves silvestres.

PALAVRAS-CHAVE: salmonelose; aves selvagens; zoonose.

\footnotetext{
'Laboratório de Estudos Ornitológicos - Universidade Estadual do Ceará - Fortaleza (CE), Brazil

${ }^{2}$ Setor de Microbiologia - Laboratório BIOLAB S/C Ltda - Fortaleza (CE), Brazil

${ }^{3}$ Coordenação - Hospital Veterinário de Caucaia - Caucaia (CE), Brazil

${ }^{4}$ Laboratório de Anatomia e Patologia Animal - Universidade Federal do Agreste de Pernambuco - Garanhuns (PE), Brazil

*Corresponding author: william.maciel@uol.com.br

Received on: 6/6/2019. Accepted on: 9/20/2020
} 


\section{INTRODUCTION}

Infectious diseases, including emerging infectious diseases, are a great threat to wildlife, animal production and human population (DASZAK et al., 2000). However, episodes of populational decrease as a consequence of these diseases in wild birds often lack proper documentation due to the scarce knowledge on emerging pathogens. In addition, screening and diagnosing wild bird populations are challenging tasks, considering the difficulty in capturing individuals for examination (BRITTINGHAM et al. 1988; LADEAU et al., 2007). Bacteria from the genus Salmonella are among the most important pathogens of interest in human and veterinary medicine due to the zoonotic potential they hold. Hence, this study aimed to review information on Salmonella spp. in free-living birds and their potential in disseminating these pathogens to domestic animals, man, and the environment.

Many species of wild birds coexist with humans and have anthropogenic sources of habitat and nutrition (BRADLEY; ALTIZER, 2007; PALOMO et al., 2013). Birds adapted to the urban life are exposed to infection and may act as disseminators of enteric zoonotic pathogens due to several factors, such as intake of contaminated food and water, polluted environments, microclimates with elevated temperature and reduced seasonality, which promote proliferation of vectors and persistence of some parasites, in addition to contact with other stressing agents causing immunosuppression, and aggregation of great number of birds in small areas, which increases the odds of contact with possible hosts (BRADLEY; ALTIZER, 2007; PALOMO et al., 2013). An inadequate habit that contributes to the presence of microorganisms in urbanized environments is bird feeding (JONES; REYNOLDS, 2008), which is related to the increased prevalence of some bacteria in these animals (BRITTINGHAM et al., 1988). This practice may favor emerging diseases due to the stimulation of reproduction in urban environments, resulting in elevated density of birds and increased concentration of feces and stress due to the interactions between individuals (DAOUST; PRESCOTT, 2007).

Some species of birds migrate thousands of kilometers through different continents and carry certain pathogens in this process (HUBÁLEK, 2004; BRUGMAN et al., 2013). Approximately $60.3 \%$ of all the emerging infectious diseases in humans are zoonoses and $71.8 \%$ originated from wild animals (JONES; REYNOLDS, 2008). According to TIZARD (2004), among these infections, salmonellosis is an emerging disease in wild birds and its prevalence have been documented since the 1960s.

Modification of the natural environment by human action may cause a superposition of the natural habitat of birds with urban, agricultural or fishing areas, which may increase the transmission of zoonotic pathogens, such as Salmonella spp. (LILLEHAUG et al., 2005). This bacterium may resist for months in humid soil, feces and water, and may cause new infections in birds (MURRAY, 1991; BÖHM,
1993; WINFIELD; GROISMAN, 2003). Its prevalence in free-living birds is influenced by factors such as diet, environment, exposure to antibiotics, infection by pathogenic microorganisms and migration patterns (PALMGREN et al., 1997; LU et al., 2003; GABRIEL et al., 2005; SKOV et al., 2008). Salmonellosis in birds occurs as a result of temporary colonization of the digestive tract by environmental strains. In addition, infections caused by strains that are adapted to the host may occur, which may or may not be pathogenic (TIZARD, 2004). Hence, depending on the strain, the bird may present an asymptomatic condition or die.

Asymptomatic cases of infection by Salmonella spp. present great relevance. Carriers may shed bacteria without clinical evidence (CONNOLLY et al., 2006). KLAASSEN et al. (2012) suggest that some stressful conditions may act as a trigger for the bird to develop and disseminate Salmonella in the environment, such as cold weather, behavioral alterations, and the prereproduction cycle (MORENO et al., 2003).

Some Salmonella strains were identified as specific pathogens of birds in 1889, when Klein isolated Salmonella ser. Gallinarum (BARROW, 1993) and Rettger identified S. ser. Gallinarum biovar Pullorum in 1899 (RETTGER, 1909). These pathogens cause fowl typhoid and pullorum disease, respectively, which have been more frequently reported in Galliformes reared in domestic environment (GAST, 2008). In free-living birds, both serotypes were rarely reported. Salmonella ser. Gallinarum biovar Pullorum was isolated from buff-necked ibis (Theristicus caudatus) that lived near a poultry production in Brazil (SOUSA et al., 2010a). In the United Kingdom, $S$. ser. Gallinarum have been isolated from rooks (Corvus frugilegus) and common wood pigeons (Columba palumbus) that lived in regions where fowl typhoid was occurred frequently (HARBOURNE, 1955). In 2012, S. ser. Gallinarum was isolated from a red-winged blackbird (Agelaius phoeniceus) in the United States (HAMER et al., 2012).

In the scientific literature, a predominance of Salmonella ser. Typhimurium (ST) as a cause of mortality in free-living birds occurs, affecting especially birds from Passeridae and Fringillidae families, which are mostly granivorous species (MIKAELIAN et al., 1997; HUDSON et al., 2000; UNE et al., 2008; GIOVANNINI et al., 2013; VELARDE et al., 2012). Epizooties in free-living birds by $S$. ser. Typhimurium were described for the first time in Switzerland during the 1950s (BOUVIER et al., 1955). Since then, several other reports were published. In 1999, an outbreak of gastroenteritis caused by $S$. ser. Typhimurium DT40 in humans and cats in the center of Sweden was associated with infections and mortality in wild birds, especially in common redpolls (Carduelis flammea) and Eurasian siskins (Carduelis spinus) (TAUNI; ÖSTERLUND, 2000). Salmonella ser. Typhimurium was pointed as the cause of mortality in wild birds from winter 1997 to summer 1998 in the eastern North America. Most affected species in these areas were pine siskin (Spinus pinus), 
purple finches (Carpodacus purpureus), evening grosbeaks (Coccothraustes vespertinus) and American goldfinches (Carduelis tristis) (DAOUST et al., 2000). REFSUM et al. (2003) reported an outbreak caused by $S$. ser. Typhimurium in $64.8 \%$ of wild Passeriformes found dead in a bird feeding station, and the following species were most affected: Eurasian siskins (C. spinus), purple finches (C. purpureus), common redpolls (C. flammea) and European greenfinches (Carduelis chloris).

Outbreaks related to free-living birds and humans have also been reported. In Great Britain, the access of sparrows to a kitchen resulted in fecal contamination of food, which originated two outbreaks of gastroenteritis (caused by $S$. ser. Typhimurium DT40 and DT160) in hospitalized patients (PENFOLD et al., 1979). ALLEY et al. (2002) reported an outbreak of $S$. ser. Typhimurium DT160 causing enteric disease in humans and mortality in sparrows (Passer domesticus), European greenfinches (C. chloris), European goldfinches (Carduelis carduelis) and common blackbirds (Turdus merula) that lived in rural areas of New Zealand. More recently, the occurrence of identical genotypes of $S$. ser. Typhimurium were isolated from wild bird populations and humans in Germany (HAUSER et al., 2009).

In addition to the mentioned above, many other serotypes of Salmonella have also been isolated from free-living bird in numerous parts of the world, especially in North America and Europe (Table 1).
A group of birds that deserve special attention are predators, considering that they may identify weakened birds and attack (GRANT et al., 2007). However, they may harbor Salmonella in greater proportion than nonpredatory birds (RECHE et al., 2003; MILLÁN et al., 2004; MOLINA-LOPEZ et al., 2011). A variety of serotypes have been isolated from cloacal swabs or organ samples collected from different species of birds of prey, such as $S$. ser. Typhimurium, $S$. ser. Tuindorp, $S$. ser. Enteritidis, $S$. ser. Newport and $S$. ser. Pajala (Table 1). Some species, such as the peregrine falcon (Falco peregrinus), are possible disseminators of these pathogens. HERNANDEZ et al. (2012) explain that the diet of this species consists mostly of birds from the Charadridae and Laridae families. Hence, peregrine falcons are migratory birds that reach great distances and may disseminate this pathogen through several areas, including those unoccupied by man.

Migratory birds are epidemiologically relevant for the possibility of acting as long-distance disseminators of pathogens that may affect man and animals (TAUNI; ÖSTERLUND, 2000). FENLON (1981) found that $72 \%$ of the serotypes isolated from human cases in Grampian, Scotland, were found in seagulls, and suggested that this was the result of them feeding on untreated sewage disposal. The European herring gull (Larus argentatus) species was reported as a probable source of S. ser. Montivideo for sheep and cattle (COULSON et al., 1983).

Table 1. Occurrence of Salmonella serotypes in wild birds.

\begin{tabular}{|c|c|c|c|}
\hline Reference & Location & Bird species & Salmonella serotypes \\
\hline NEEL et al. (1953) & Iran & Corvus corax & S. ser. Hessarek \\
\hline HARBOURNE (1955) & United Kingdom & $\begin{array}{l}\text { Corvus frugilegus, Columba } \\
\text { palumbus, Perdix perdix }\end{array}$ & S. ser. Thompson, S. ser. Gallinarum \\
\hline $\begin{array}{l}\text { RADWAN; LAMPKY } \\
(1972)\end{array}$ & United States & Molothrus ater & $\begin{array}{l}\text { S. ser. Typhimurium, S. ser. Paratyphi A e B, } \\
\text { S. ser. Albany }\end{array}$ \\
\hline SPECKMANN (1975) & England & Cygnus olor & S. ser. Typhimurium \\
\hline FREITAS et al. (1977) & Brazil & Ardea alba & S. ser. Typhimurium \\
\hline PLANT (1978) & England & Prunella modularis & S. ser. Anatum \\
\hline FENLON (1981) & United Kingdom & Larus spp. & $\begin{array}{l}\text { S. ser. Typhimurium, S. ser. Derby, S. ser. Give, } \\
\text { S. ser. Panama, S. ser. Agona, S. ser. Chester, } \\
\text { S. ser. Virchow } \\
\text { +more than ten serotypes }\end{array}$ \\
\hline COULSON et al. (1983) & $\begin{array}{l}\text { Scotland \& } \\
\text { England }\end{array}$ & Larus argentatus & $\begin{array}{l}\text { S. ser. Montivideo, S. ser. Heidelberg, } \\
\text { S. ser. Hadar, S. ser. Agona, } \\
\text { (more than ten serotypes) }\end{array}$ \\
\hline FENLON (1983) & Scotland & Larus spp. & $\begin{array}{l}\text { S. ser. Stanley, S. ser. Typhimurium } \\
\text { (DT } 40 \text { and DT } 1 \text { 10), S. ser. Virchow, } \\
\text { S. ser. Binza, S. ser. Newport, S. ser. Ohio, } \\
\text { S. ser. Schwarzengrund }\end{array}$ \\
\hline FRICKER (1984) & United Kingdom & Larus ridibundus & $\begin{array}{l}\text { S. ser. Agona, S. ser. Anatum, S. ser. Bredeney, } \\
\text { S. ser. Derby, S. ser. Infantis, S. ser. Panama, } \\
\text { S. ser. Saintpaul, S. ser. Stanley, S. ser. Tokaradi, } \\
\text { S. ser. Typhimurium, S. ser. Virchow }\end{array}$ \\
\hline
\end{tabular}


Table 1. Continuation.

\begin{tabular}{|c|c|c|c|}
\hline Reference & Location & Bird species & Salmonella serotypes \\
\hline GIRDWOOD et al. (1985) & Scotland & Larus fuscus, Larus ridibundus & $\begin{array}{l}\text { S. ser. Virchow, S. ser. Typhimurium, } \\
\text { S. ser. Bredeney, S. ser. Hadar, S. ser. Infantis, } \\
\text { (more than ten serotypes) }\end{array}$ \\
\hline $\begin{array}{l}\text { KIRKPATRICK; COLVIN } \\
\text { (1986) }\end{array}$ & United States & Tyto furcata & $\begin{array}{l}\text { S. ser. Typhimurium, S. ser. Tuindorp, } \\
\text { S. ser. Thompson }\end{array}$ \\
\hline $\begin{array}{l}\text { KIRKPATRICK; TREXLER- } \\
\text { MYREN (1986) }\end{array}$ & United States & Buteo jamaicensis & S. ser. Enteritidis, S. ser. Newport \\
\hline LITERÁK et al. (1992) & Czech Republic & Larus ridibundus & $\begin{array}{l}\text { S. ser. Typhimurium, S. ser. Derby, } \\
\text { S. ser. Enteriditis, S. ser. Hadar, S. ser. Agona, } \\
\text { S. ser. Infantis, S. ser. Montivideo, S. ser. Abony }\end{array}$ \\
\hline QUESSY; MESSIER (1992) & Canada & Larus delawarensis & $\begin{array}{l}\text { S. ser. Hadar, S. ser. Montivideo, S. ser. } \\
\text { Heidelberg, S. ser. Infantis, S. ser. Berta, } \\
\text { S. ser. Kentucky, S. ser. Thompson, } \\
\text { S. ser. Mamilla, S. ser. Typhimurium }\end{array}$ \\
\hline LÉVESQUE et al. (1993) & Canada & Larus delawarensis & $\begin{array}{l}\text { S. ser. Brandenburg, S. ser. Agona, } \\
\text { S. ser. Hadar, S. ser. Stanley, S. ser. Anatum, } \\
\text { S. ser. Typhimurium }\end{array}$ \\
\hline ĈİẐEK et al. (1994) & Czech Republic & $\begin{array}{l}\text { Larus ridibundus, } \\
\text { Passer domesticus, Parus major, } \\
\text { Columba livia, Parus montanus, } \\
\text { (more than ten species) }\end{array}$ & $\begin{array}{l}\text { S. ser. Typhimurium, S. ser. Enteritidis, } \\
\text { S. ser. Agona, S. ser. Hadar (more than ten } \\
\text { serotypes) }\end{array}$ \\
\hline OLSEN et al. (1996) & Iceland & Pygoscelis papua & S. ser. Enteritidis \\
\hline MIKAELIAN et al. (1997) & Canada & $\begin{array}{c}\text { Passer domesticus, } \\
\text { Bubo virginianus, Rissa tridactyla, } \\
\text { Larus delawarensis }\end{array}$ & S. ser. Typhimurium (*) \\
\hline PALMGREN et al. (1997) & Sweden & Larus ridibundus & S. ser. Typhimurium (DT 22) \\
\hline PALMGREN et al. (2000) & Georgia & $\begin{array}{c}\text { Pygoscelis papua, } \\
\text { Diomedea melanophris }\end{array}$ & $\begin{array}{l}\text { S. ser. Typhimurium (DT150), S. ser. Havana } \\
\text { (PT4, PT4-Like, PT35), S. ser. Enteritidis, } \\
\text { S. ser. Newport }\end{array}$ \\
\hline FRERE et al. (2000) & Argentina & Larus dominicanus & S. ser. Typhimurium \\
\hline HUDSON et al. (2000) & United States & $\begin{array}{l}\text { Molothrus sp., Carduelis sp. } \\
\text { and Passer sp. }\end{array}$ & S. ser. Typhimurium $\left(^{*}\right)$ \\
\hline SMITH et al. (2002) & United States & $\begin{array}{l}\text { Circus cyaneus, } \\
\text { Larus occidentalis }\end{array}$ & $\begin{array}{l}\text { S. ser. Montevideo, S. ser. Typhimurium } \\
\text { 4,5,12:1 monophasic, S. ser. Ohio, } \\
\text { S. ser. Johannesberg }\end{array}$ \\
\hline ALLEY et al. (2002) & New Zealand & $\begin{array}{c}\text { Passer domesticus, } \\
\text { Carduelis chloris, } \\
\text { Carduelis carduelis, Turdus merula }\end{array}$ & S. ser. Typhimurium DT $160\left(^{*}\right)$ \\
\hline DUARTE et al. (2002) & Portugal & Larus fuscus, Larus cachinnans & $\begin{array}{l}\text { S. ser. Typhimurium, S. ser. Hadar, } \\
\text { S. ser. Bardo, S. ser. Newport, S. ser. Derby, } \\
\text { S. ser. Enteritidis, S. ser. Infantis (more than } \\
\text { ten serotypes) }\end{array}$ \\
\hline KIRK et al. (2002) & United States & $\begin{array}{l}\text { Passer domesticus, Molothrus } \\
\text { ater, Euphagus cyanocephalus, } \\
\text { Carpodacus mexicanus, Sturnus } \\
\text { vulgaris, Agelaius phoeniceus }\end{array}$ & $\begin{array}{l}\text { S. ser. Montevideo, S. ser. Meleagridis, } \\
\text { S. ser. Muenster, S. ser. Typhimurium }\end{array}$ \\
\hline REFSUM et al. (2002) & Norway & $\begin{array}{l}\text { Pyrrhula pyrrhula, Carduelis } \\
\text { chloris, Carduelis spinus, Carduelis } \\
\text { flammea, Passer domesticus } \\
\text { (more than ten species) }\end{array}$ & $\begin{array}{l}\text { S. ser. Typhimurium 0:4,12 (DT 40, U277, DT } \\
99 \text { and DT } 110)\left(^{*}\right)\end{array}$ \\
\hline
\end{tabular}


Table 1. Continuation.

\begin{tabular}{|c|c|c|c|}
\hline Reference & Location & Bird species & Salmonella serotypes \\
\hline RECHE et al. (2003) & Spain & $\begin{array}{c}\text { Falco naumanni, Aquila heliaca, } \\
\text { Athene noctua, Tyto furcata, } \\
\text { Buteo buteo, Asio otus, } \\
\text { Gyps fulvus }\end{array}$ & $\begin{array}{l}\text { S. ser. Enteritidis (PT6a, PNR), S. ser. Adelaide, } \\
\text { S. ser. Brandemburgo, S. ser. Newport, } \\
\text { S. ser. Typhimurium, S. ser. Hadar, } \\
\text { S. ser. Saintpaul, S. ser. Virchow }\end{array}$ \\
\hline REFSUM et al. (2003) & Norway & $\begin{array}{l}\text { Pyrrhula pyrrhula, } \\
\text { Carduelis spinus, } \\
\text { Carduelis flammea, } \\
\text { Carduelis chloris, } \\
\text { (more than ten species) }\end{array}$ & S. ser. Typhimurium 4,12:i:1,2 (*) \\
\hline VLAHOVIĆ et al. (2004) & Croatia & $\begin{array}{l}\text { Columba livia, } \\
\text { Corvus frugilegus, Buteo buteo, } \\
\text { Larus ridibundus, Strix aluco }\end{array}$ & S. ser. Typhimurium, S. ser. Enteritidis \\
\hline TANAKA et al. (2005) & Japan & Columba livia & Salmonella spp. \\
\hline DOBBIN et al. (2005) & Canada & Phalacrocorax auritus & S. ser. Typhimurium \\
\hline FERRAZZI et al. (2005) & Italy & Corvus cornix & S. ser. Typhimurium \\
\hline LILLEHAUG et al. (2005) & Norway & Anser anser & S. ser. Diarizona \\
\hline EPSTEIN et al. (2006) & Australia & Threskiornis molucca & Salmonella spp. \\
\hline PENNYCOTT et al. (2006) & Great Britain & $\begin{array}{c}\text { Carduelis chloris, } \\
\text { Passer domesticus, Fringilla coelebs, } \\
\text { Carduelis carduelis, Passer } \\
\text { montanus, Carduelis spinus, Parus } \\
\text { major, Accipiter nisus, Strix aluco, } \\
\text { Corvus frugilegus, Columba livia, } \\
\text { Larus ridibundus, Larus canus, } \\
\text { Larus marinus, Larus argentatus, } \\
\text { Larus fuscus }\end{array}$ & $\begin{array}{l}\text { S. ser. Typhimurium (DT2, DT99, DT41, } \\
\text { DT 104, DT195, DT56) }\left(^{*}\right)\end{array}$ \\
\hline PALMGREN et al. (2005) & Sweden & Larus ridibundus & S. ser. Typhimurium (DT1 15, DT41, DT120) \\
\hline KOCABIYIK et al. (2006) & Turkey & Bubo bubo & S. ser. Enteritidis (PT21b) $\left(^{*}\right)$ \\
\hline ĈÎ́EK et al. (2007) & Czech Republic & Larus ridibundus & $\begin{array}{l}\text { S. ser. Typhimurium (DT 104), S. Enteritidis, } \\
\text { S. ser. Panama, S. ser. Kentucky (more than ten } \\
\text { serotypes) }\end{array}$ \\
\hline LITERÁK et al. (2007) & Czech Republic & Corvus frugilegus & S. ser. Enteritidis (PT8, PT23) \\
\hline GRANT et al. (2007) & United Kingdom & $\begin{array}{l}\text { Carduelis chloris, } \\
\text { Passer domesticus, } \\
\text { Sturnus vulgaris, Fringilla } \\
\text { coelebs, Turdus merula }\end{array}$ & S. ser. Typhimurium (DT56, DT40) \\
\hline JIJÓN et al. (2007) & United States & $\begin{array}{l}\text { Parabuteo unicinctus, } \\
\text { Otus asio }\end{array}$ & S. ser. Saintpaul, S. enterica houtenae \\
\hline ALBARNAZ et al. (2007) & Brazil & Larus dominicanus & S. ser. Typhimurium \\
\hline UNE et al. (2008) & Japan & Passer montanus & S. ser. Typhimurium (DT40) $\left(^{*}\right)$ \\
\hline ALLGAYER et al. (2009) & Brazil & Anodorhynchus hyacinthinus & S. ser. Braenderup \\
\hline IVESON et al. (2009) & Australia & $\begin{array}{l}\text { Eudyptula minor, Anous } \\
\text { stolidus, Anous tenuirostris, } \\
\text { Onychoprion fuscatus }\end{array}$ & $\begin{array}{l}\text { S. ser. Bovismorbificons, S. ser. Derby, } \\
\text { S. ser. Panama, S. ser. Saintpaul, S. ser. } \\
\text { Muenchen, S. Typhimurium, S. ser. Adelaide, } \\
\text { S. ser. Havana, S. ser. Infantis }\end{array}$ \\
\hline DIMITROV et al. (2009) & Antarctica & Pygoscelis papua & S. ser. Typhimurium, S. ser. Enteritidis \\
\hline KITADAl et al. (2010) & China & $\begin{array}{l}\text { Grus monacha, Grus vipio, } \\
\text { Grus grus }\end{array}$ & $\begin{array}{l}\text { S. ser. Typhimurium, S. ser. Hvittingfoss, } \\
\text { S. ser. Abaetetuba, S. ser. Enteritidis, } \\
\text { S. ser. Konstanz, S. ser. Pakiston }\end{array}$ \\
\hline
\end{tabular}


Table 1. Continuation.

\begin{tabular}{|c|c|c|c|}
\hline Reference & Location & Bird species & Salmonella serotypes \\
\hline SOUSA et al. (2010a) & Brazil & $\begin{array}{l}\text { Theristicus caudatus, Zenaida } \\
\text { auriculata, Cariama cristata }\end{array}$ & $\begin{array}{l}\text { S. ser. Muenchen, S. ser. Enteritidis, } \\
\text { S. ser. Saintpaul, S. ser. Pullorum }\end{array}$ \\
\hline PHALEN et al. (2010) & United States & Bubulcus ibis & $\begin{array}{l}\text { S. ser. Bredeney, S. ser. Anatum, S. ser. Ibadon, } \\
\text { S. ser. Mississipi, S. ser. Oranienburg, } \\
\text { S. ser. Braenderup, S. ser. Typhimurium (more } \\
\text { than ten serotypes) }\end{array}$ \\
\hline $\begin{array}{l}\text { BRUNTHALER et al. } \\
(2010)\end{array}$ & Australia & $\begin{array}{l}\text { Pyrrhula pyrrhula, Carduelis } \\
\text { spinus, Carduelis chloris }\end{array}$ & S. ser. Typhimurium $\left(^{*}\right)$ \\
\hline SOUSA et al. (2010b) & Brazil & Columba livia & S. ser. Typhimurium \\
\hline KHIDHIR (2010) & Iraq & $\begin{array}{l}\text { Streptopelia decaocto, } \\
\text { Columba livia }\end{array}$ & S. ser. Typhimurium \\
\hline PENNYCOTT et al. (2010) & Scotland & $\begin{array}{l}\text { Carduelis carduelis, Carduelis } \\
\text { spinus, Parus major, Passer } \\
\text { montanus, Passer modularis, } \\
\text { Fringilla montifringilla }\end{array}$ & $\begin{array}{l}\text { S. ser. Typhimurium (DT40, DT85, DT41, } \\
\text { DT56) }\left(^{*}\right)\end{array}$ \\
\hline HUGHES et al. (2010) & United Kingdom & $\begin{array}{l}\text { Passer domesticus, Carduelis } \\
\text { chloris, Carduelis spinus, } \\
\text { Streptopelia decaocto, } \\
\text { Columba palumbus }\end{array}$ & $\begin{array}{l}\text { S. ser. Typhimurium (DT56, DT40, DT56, } \\
\text { DT41, PT U277) (*) }\end{array}$ \\
\hline MIRZAIE et al. (2010) & Iran & Passer domesticus & $\begin{array}{l}\text { S. ser. Typhimurium, S. ser. Enteritidis, } \\
\text { S. ser. Montevideo }\end{array}$ \\
\hline VIGO et al. (2011) & Argentina & $\begin{array}{l}\text { Pygoscelis adeliae, } \\
\text { Larus dominicanus }\end{array}$ & S. ser. Enteritidis \\
\hline $\begin{array}{l}\text { LÓPEZ-MARTÍN et al. } \\
\text { (2011) }\end{array}$ & Chile & $\begin{array}{l}\text { Larus dominicanus, } \\
\text { Leucophaeus pipixcan }\end{array}$ & $\begin{array}{l}\text { S. ser. Enteritidis, S. ser. Anatum } \\
\text { S. ser. Senfteberg, S. ser. Infantis }\end{array}$ \\
\hline $\begin{array}{l}\text { MOLINA-LOPEZ et al. } \\
(2011)\end{array}$ & Spain & $\begin{array}{l}\text { Buteo buteo, Gyps fulvus, } \\
\text { Athene noctua, Bubo bubo }\end{array}$ & $\begin{array}{l}\text { S. ser. Bredeney, S. ser. Scheissheim, } \\
\text { S. ser. Rissen, S. ser. Diarizonae, S. ser. Derby, } \\
\text { S. ser. Schwarzengrund, S. ser. Muenster }\end{array}$ \\
\hline FOTI et al. (2011) & Italy & Sylvia atricapilla & S. ser. bangori 48:z35 \\
\hline $\begin{array}{l}\text { VICO; MAINAR-JAIME } \\
(2011)\end{array}$ & Spain & $\begin{array}{c}\text { Passer domesticus, Sturnus } \\
\text { vulgaris, Sylvia atricapilla, } \\
\text { Turdus merula, } \\
\text { Erithacus rubecula, } \\
\text { Luscinia megarhynchos, } \\
\text { Sylvia melanocephala }\end{array}$ & $\begin{array}{l}\text { S. ser. Typhimurium, S. ser. Braendenburg, } \\
\text { S. ser. Anatum, S. ser. Arizonae, } \\
\text { S. ser. Mikawasima, S. ser. Bredeney, } \\
\text { S. ser. Reading, S. ser. Houtenae, } \\
\text { S. ser. Kapemba }\end{array}$ \\
\hline VELARDE et al. (2012) & Spain & Turdus philomelos & S. ser. Hessarek ( $\left.{ }^{*}\right)$ \\
\hline $\begin{array}{l}\text { HERNANDEZ et al. } \\
(2012)\end{array}$ & United States & Spinus spinus & S. ser. Typhimurium $\left(^{*}\right)$ \\
\hline $\begin{array}{l}\text { HERNANDEZ et al. } \\
(2012)\end{array}$ & Sweden & Falco peregrinus & S. ser. Pajala \\
\hline HAMER et al. (2012) & United States & Agelaius phoeniceus & $\begin{array}{l}\text { S. ser. Dublin, S. ser. Typhi, S. ser. Enteritidis, } \\
\text { S. ser. Paratyphi, S. ser. Gallinarium }\end{array}$ \\
\hline LA SALA et al. (2013) & Argentina & $\begin{array}{l}\text { Larus atlanticus, } \\
\text { Larus dominicanus }\end{array}$ & S. ser. Typhimurium, S. ser. Gallinarum \\
\hline BOTTI et al. (2013) & Italy & $\begin{array}{l}\text { Columba livia, Passer domesticus, } \\
\text { Garrulus glandarius, Buteo buteo, } \\
\text { Asio otus, Tyto furcata, } \\
\text { Strix aluco, Larus spp. }\end{array}$ & $\begin{array}{l}\text { S. ser. Typhimurium (DT104, DT 12, DT 193, } \\
\text { DT302), S. ser. Enteritidis (PT4) (more than } \\
\text { ten serotypes) }\end{array}$ \\
\hline
\end{tabular}


Table 1. Continuation.

\begin{tabular}{|c|c|c|c|}
\hline Reference & Location & Bird species & Salmonella serotypes \\
\hline ANDRÉS et al. (2013) & Spain & $\begin{array}{c}\text { Sturnus vulgaris, Motacilla } \\
\text { alba, Columba livia, Sylvia } \\
\text { atricapilla, Passer domesticus, } \\
\text { Hirundo rustica, Cettia cetti }\end{array}$ & $\begin{array}{l}\text { S. ser. Typhimurium 4,12:i: 1,2, S. ser. Arizona, } \\
\text { S. ser. Diarizona, S. ser. Mikawasima } \\
\text { 6:7:y:e,n,z 15, S. ser. Anatum }\end{array}$ \\
\hline BORRELLI et al. (2013) & Italy & Apus apus & S. ser. Infantis \\
\hline PEDERSEN et al. (2013) & United States & Cygnus olor & $\begin{array}{l}\text { S. ser. Typhimurium (DT 104), } \\
\text { S. ser. Braenderup }\end{array}$ \\
\hline SULZNER et al. (2014) & United States & Cathartes aura & $\begin{array}{l}\text { S. ser. Anatum, S. ser. Newport, } \\
\text { S. ser. Montevideo, S. ser. Arizonae, } \\
\text { S. ser. Enteritidis, S. ser. Typhimurium }\end{array}$ \\
\hline LAWSON et al. (2014) & England & $\begin{array}{c}\text { Carduelis chloris, Passer } \\
\text { domesticus }\end{array}$ & S. ser. Typhimurium (*) \\
\hline AFEMA (2014) & Uganda & $\begin{array}{l}\text { Mimus migrans, Ceryle } \\
\text { rudis, Egretta garzetta, } \\
\text { Ardeola ralloides, Alopochen } \\
\text { aegyptiacus, Anas undulata, } \\
\text { Ardea goliath, Ardea cinerea, } \\
\text { Ardea melanocephala, } \\
\text { Mesophoyx intermedia, } \\
\text { Burhinus vermiculatus }\end{array}$ & $\begin{array}{l}\text { S. ser. Stanleyville, S. ser. Typhimurium, } \\
\text { S. ser. Newport, S. ser. Chandans, } \\
\text { S. ser. Kentucky (more than ten serotypes) }\end{array}$ \\
\hline FUKUl et al. (2014) & Japan & Passer monatus & S. ser. Typhimurium (DT40) $\left(^{*}\right)$ \\
\hline DIAS et al. (2014) & Brazil & $\begin{array}{l}\text { Chrysomus ruficapillus, } \\
\text { Sicalis flaveola }\end{array}$ & Salmonella enterica \\
\hline BLANCO (2015) & Spain & Milvus milvus & S. ser. Typhimurium 4,5, $12: \mathrm{i}$ \\
\hline KRAWIEC et al. (2015) & Poland & $\begin{array}{c}\text { Anas platyrhynchos, Carduelis } \\
\text { cabaret, Cyanistes caeruleus, } \\
\text { Corvus fringillarius, Sturnus } \\
\text { vulgaris, Carduelis spinus, } \\
\text { Carduelis chloris }\end{array}$ & $\begin{array}{l}\text { S. ser. Typhimurium 4, 12:i: 1,2, S. ser. Infantis } \\
\text { 6,7:v: 1,5, S. ser. Virchow, S. ser. Hadar, } \\
\text { S. ser. Salamae, S. ser. Houtenae }\end{array}$ \\
\hline VAN ANDEL et al. (2015) & New Zealand & $\begin{array}{l}\text { Notiomystis cincta, } \\
\text { Vanellus miles, } \\
\text { Philesturnus carunculatus }\end{array}$ & $\begin{array}{l}\text { S. ser. Saintpaul, S. enterica subspecies } \\
\text { houatenae }\left(^{*}\right)\end{array}$ \\
\hline HERNANDEZ et al. (2016) & United States & Eudocimus albus & $\begin{array}{l}\text { S. ser. Anatum, S. ser. Baildon, S. ser. Newport, } \\
\text { S. ser. Rubislow, S. ser. Typhimurium (more } \\
\text { than ten serotypes) }\end{array}$ \\
\hline ROUFFAER et al. (2016) & Belgium & Passer domesticus & S. ser. Typhimurium (DT99, DT195) \\
\hline $\begin{array}{l}\text { HAESENDONCK et al. } \\
(2016)\end{array}$ & Belgium & Columba livia & S. ser. Enteritidis (PT4) \\
\hline $\begin{array}{l}\text { LIAKOPOULOS et al. } \\
(2016)\end{array}$ & Argentina & Larus dominicanus & S. ser. Heidelberg \\
\hline $\begin{array}{l}\text { JURADO-TARIFA et al. } \\
(2016)\end{array}$ & Spain & $\begin{array}{c}\text { Gyps fulvus, Falco naumanni, } \\
\text { Falco tinnunculus, Accipiter } \\
\text { nisus, Milvus nigrans, Buteo } \\
\text { buteo, Asio otus, Bubo bubo, } \\
\text { Athene noctua, Otus scops, Anas } \\
\text { platyrhynchos, Anser anser }\end{array}$ & $\begin{array}{l}\text { S. ser. Typhimurium, S. ser. Enteritidis, } \\
\text { S. ser. Mikawasima, S. ser. Montevideo, } \\
\text { S. ser. Bredney, S. ser. Anatum }\end{array}$ \\
\hline AFEMA; SISCHO (2016) & Uganda & $\begin{array}{l}\text { Mimus migrans, Ceryle rudis, } \\
\text { Alopochen aegyptiacus, } \\
\text { Ardea cinerea (more } \\
\text { than ten species) }\end{array}$ & $\begin{array}{l}\text { S. ser. Chandans, S. ser. Heidelberg, } \\
\text { S. ser. Newport, S. ser. Senftemberg, } \\
\text { S. ser. Stanleyvilte }\end{array}$ \\
\hline
\end{tabular}


Table 1. Continuation.

\begin{tabular}{lccc} 
Reference & Location & Bird species & Salmonella serotypes \\
CAMACHO et al. (2016) & $\begin{array}{c}\text { Iberian } \\
\text { Peninsula }\end{array}$ & Ciconia ciconia & Salmonella spp. \\
\hline EBERT et al. (2016) & Brazil & Larus dominicanus & S. ser. Enteritidis \\
\hline BROBEY et al. (2017) & United States & $\begin{array}{c}\text { Cyanocitta cristata, } \\
\text { Sphyrapicus varius, Melanerpes } \\
\text { carolinus, Columbina inca, } \\
\text { Spinus tristis, Cardinalis } \\
\text { cardinalis, Zenaida macroura }\end{array}$ & Salmonella spp. \\
\hline
\end{tabular}

*Studies in which outbreaks or deaths occurred

Other studies reporting Salmonella serotypes in asymptomatic migratory birds were reported in United Kingdom (FRICKER, 1984), Czech Republic (LITERÁK et al., 1992), Canada (QUESSY; MESSIER, 1992) Sweden (PALMGREN et al., 2000), Argentina (FRERE et al., 2000; LIAKOPOULOS et al., 2016), Brazil (ALBARNAZ et al., 2007; EBERT et al., 2016) and Chile (LÓPEZ-MARTÍN et al., 2011).

This study presents published scientific evidence suggesting the direct and indirect role of wild birds in the transmission of Salmonella to humans. Foremost, there are no real evidence for the direct transmission of free-living birds to humans, in addition to the rare cases that occur under exceptional circumstances. Theoretically, several human infections may be transmitted by these animals. However, the scientific base for most of these associations remains speculative. The review demonstrated that carrier birds are probably important in maintaining active sources of infections, which may implicate in epizooties of salmonellosis. However, most of the findings are related to the presence of the pathogen in an asymptomatic manner and the influence of environmental factors in the epidemiology of extensive epizooties remain unknown.

ACKNOWLEDGEMENTS: Not applicable.

FUNDING: This study was financed in part by the Coordenação de Aperfeiçoamento de Pessoal de Nível Superior - Brasil (CAPES) Finance Code 001.

CONFLICTS OF INTEREST: All authors declare that they have no conflict of interest.

ETHICAL APPROVAL: Not applicable.

AVAILABILITY OF DATA AND MATERIAL: Data sharing not applicable to this article as no datasets were generated or analyzed during the current study.

AUTHORS' CONTRIBUTIONS: All authors had the idea for the article, who performed the literature search and data analysis, and who drafted and/or critically revised the work.

| || | | | | | | | | | | | | | | | | | | | | | | | | | | | | | | | | | | | | | | | | | | | | | | | | | | | | | | | | | | | | | | | | | | | | | | | | | | | | | | | | | | | | | | | | | | | | | | | | | | | | | | | | | | | | | | | | | | | | | | | | | | | | | | | | | | | | | | | | | | | | | | | | | | | | | | | | | | | | | | | | | | | | | | | | | | | | | | | | | | | | | | | | | | | | | | | | | | | |

\section{REFERENCES}

AFEMA, J.A. Salmonella and antimicrobial resistance in humans, livestock and wild birds. 2014. Dissertation (Doctor of Philosophy) - Washington State University, Washington, 2014. Available from: https://research. libraries.wsu.edu/xmlui/bitstream/handle/2376/5438/ Afema_wsu_0251E_1 1262.pdf?sequence= 1 \&isAllowed $=y$. Access on: 17 Apr. 2018.

AFEMA, J.A.; SISCHO, W.M. Salmonella in Wild Birds Utilizing Protected and Human Impacted Habitats, Uganda. EcoHealth, New York, v.13, n.3, p.558-569, 2016. https://doi.org/10.1007/ s10393-016-1149-1
ALBARNAZ, J.D.; TOSO, J.; CORRÊA, A.A.; SIMÕES C.M.O.; BARARDI, C.R.M. Relationship between the contamination of gulls (Larus dominicanus) and oysters (Crassostrea gigas) with Salmonella serovar Typhimurium by PCR-RFLP. International Journal of Environmental Health Research, Macon, v. 17, n.2, p.133-140, 2007. https://doi.org/10.1080/09603120701219816

ALLEY, M.R.; CONNOLLY, J.H.; FENWICK, S.G.; MACKERETH, G.F.; LEYLAND, M.J.; ROGERS, L.E.; HAYCOCK, M.; NICOL, C.; REED, C.E.M. An epidemic of salmonellosis caused by Salmonella Typhimurium DT 160 in wild birds and humans in New Zealand. New Zealand Veterinary Journal, Wellington, v.50, n.5, p.170-176, 2002. https://doi.org/10.1080/00480169.2002.36306 
ALLGAYER, M.C.; OLIVEIRA, S.J.; MOTTIN, V.D.; LOIKO, M.R.; ABILLEIRA, F.; GUEDES, N.M.R.; PASSOS, D.T.; WEIMER, T.A. Isolamento de Salmonella Braenderup em arara-azul (Anodorhynchus hyacinthinus). Ciência Rural, Santa Maria, v.39, n.8, p.2542-2545, 2009. https://doi.org/10.1590/S0103-84782009005000171

ANDRÉS, S.; VICO, J.P.; GARRIDO, V.; GRILLÓ, M.J.; SAMPER, S.; GAVÍN, P.; HERRERA-LEÓN, S.; MAINAR-JAIME, R.C. Epidemiology of Subclinical Salmonellosis in Wild Birds from an Area of High Prevalence of Pig Salmonellosis: Phenotypic and Genetic Profiles of Salmonella Isolates. Zoonoses and Public Health, Weinheim, v.60, n.5, p.355-365, 2013. https://doi. org/10.1111/j.1863-2378.2012.01542.x

BARROW, P.A. Salmonella control - past, present and future. Avian Pathology, London, v.22, n.4, p.651-669, 1993. https:// doi.org/10.1080/03079459308418954

BLANCO, G. Multiresistant Salmonella Serovar Typhimurium Monophasic in Wintering Red Kites (Milvus milvus) in Segovia, Central Spain. Journal of Raptor Research, West Chester, v.49, n.3, p.337-341, 2015. https://doi.org/10.3356/JRR-14-56.1

BÖHM, R. Behavior of selected salmonellae in the environment. Deutsche Tierarztliche Wochenschrift, Berlin, v.100, n.7, p.275278, 1993. Available from: https://pubmed.ncbi.nlm.nih. gov/8375321/. Access on: 13 Apr. 2018.

BORRELLI, L.; FIORETTI, A.; RUSSO, T.P.; BARCO, L.; RAIA, P.; BOSSA, L.M.L.; SENSALE, M.; MENNA, L.F.; DIPINETO, L. First report of Salmonella enterica serovar Infantis in common swifts (Apus apus). Avian Pathology, London, v.42, n.4, p.323-326, 2013. https://doi.org/10.1080/03079457.2013.799262

BOTTI, V.; NAVILLOD, F.V.; DOMENIS, L.; ORUSA, R.; PEPE, E.; ROBETTO, S.; GUIDETTI, C. Salmonella spp. e antibiotico-resistenza in Mammiferi e Uccelli selvatici in Italia nord-occidentale dal 2002 al 2010. Veterinaria Italiana, Teramo, v.49, n.2, p.187-294, 2013. https://doi.org/10.12834/Vetlt.2013.492.193.200

BOUVIER, G.; BURGISSER, H.; SCHNEIDER, P.A. Observations on diseases in game, birds and fish in 1953 and 1954. Schweizer Archiv für Tierheilkunde, Bern, v.97, p.318-325, 1955.

BRADLEY, C.A.; ALTIZER, S. Urbanization and the ecology of wildlife diseases. Trends in Ecology \& Evolution, Maryland Heights, v.22, n.2, p.95-102, 2007. https://doi.org/10.1016/j. tree.2006.11.001

BRITTINGHAM, M.C.; TEMPLE, S.A.; DUNCAN, R.M. A survey of the prevalence of selected bacteria in wild birds. Journal of Wildlife Diseases, Lawrence, v.24, n.2, p.299-307, 1988. https://doi. org/10.7589/0090-3558-24.2.299

BROBEY, B.; KUCKNOOR, A.; ARMACOST, J. Prevalence of Trichomonas, Salmonella, and Listeria in Wild Birds from Southeast Texas. Avian Diseases, Jacksonville, v.61, n.3, p.347-352, 2017. https://doi.org/10.1637/1 1607-020617-RegR

BRUGMAN, V.A.; HORTON, D.L.; PHIPPS, L.P.; JOHNSON, N.; COOK, A.J.C.; FOOKS, A.R.; BREED, A.C. Epidemiological perspectives on West Nile virus surveillance in wild birds in Great Britain. Epidemiology \& Infection, Cambridge, v.141, n.6, p. 1 134-1142, 2013. https://doi.org/10.1017/S095026881200177X
BRUNTHALER, R.; SPERGSER, J.; LOUPAL, G. Salmonellosis and Macrorhabdiosis in Passerine Birds in Austria During Winter 2009-2010. Journal of Comparative Pathology, Belfast, v.143, n.4, p.348, 2010. https://doi.org/10.1016/j.jcpa.2010.09.168

CAMACHO, M.C.; HERNÁNDEZ, J.M.; LIMA-BARBERO, J.F.; HÖFLE, U. Use of wildlife rehabilitation centres in pathogen surveillance: A case study in white storks (Ciconia ciconia). Preventive Veterinary Medicine, Berlin, v.130, p. 106-111, 2016. https://doi.org/10.1016/j.prevetmed.2016.06.012

ĈÎẐEK, A.; DOLEJSKÁ, M.; KARPÍŠKOVÁ, R.; DĚDIČOVÁ, D.; LITERÁK, I. Wild black-headed gulls (Larus ridibundus) as an environmental reservoir of Salmonella strains resistant to antimicrobial drugs. European Journal of Wildlife Research, Ciudad Real, v.53, n.1, p.55-60, 2007. https://doi.org/10.1007/ s10344-006-0054-2

ĈÎẐEK, A.; LITERÁK, I.; HEJLÍĆEK, K.; TREML, F.; SMOLA, J. Salmonella contamination of the environment and its incidence in wild birds. Journal of Veterinary Medicine, Series B, Weinheim, v.41, n. 1-10, p.320-327, 1994.https://doi.org/10.1111/j.1439-0450.1994. tb00234.x

CONNOLLY, J.H.; ALLEY, M.R.; DUTTON, G.J.; ROGERS, L.E. Infectivity and persistence of an outbreak strain of Salmonella enterica serotype Typhimurium DT 160 for house sparrows (Passer domesticus) in New Zealand. New Zealand Veterinary Journal, Wellington, v.54, n.6, p.329-332, 2006. https://doi. org/10.1080/00480169.2006.36719

COULSON, J.C.; BUTTERFIELD, J.; THOMAS, C. The herring gull Larus argentatus as a likely transmitting agent of Salmonella montevideo to sheep and cattle. Epidemiology $\odot$ Infection, Cambridge, v.91, n.3, p.437-443, 1983. https://doi.org/10.1017/ S0022172400060472

DAOUST, P.-Y.; BUSBY, D.G.; FERNS, L.; GOLTZ, J.; MCBURNEY, S.; POPPE, C.; WHITNEY, H. Salmonellosis in songbirds in the Canadian Atlantic provinces during winter-summer 1997-98. The Canadian Veterinary Journal, Guelph, v.4 1, n. 1, p.54-59, 2000. Available from: https://pubmed.ncbi.nlm.nih.gov/10642873/. Access on: 7 Jul. 2017.

DAOUST, P.-Y.; PRESCOTT, J.F. Salmonellosis. In: THOMAS, N.J.; HUNTER, D.B; ATKINSON, C.T. (eds). Infectious Diseases of Wild Birds. Ames: Blackwell, 2007. chap.13, p.270-288. https://doi. org/10.1002/9780470344668.ch 13

DASZAK, P.; CUNNINGHAM, A.A.; HYATT, A.D. Emerging Infectious Diseases of Wildlife--Threats to Biodiversity and Human Health. Science, Washington, v.287, n.5452, p.443-449, 2000. https:// doi.org/10.1126/science.287.5452.443

DIAS, P.A.; WILSMANN, D.E.; HEINEN, J.G.; CORSINI, C.D.; CALABUIG, C.; TIMM, C.D. Primeiro relato de Salmonella enterica e Campylobacter spp. isolados de Garibaldi (Chrysomus ruficapillus) e Canário-da-terra (Sicalis flaveola) silvestres. Revista do Instituto Adolfo Lutz, São Paulo, v.73, n.4, p.368-371, 2014. Available from: https://www.bvs-vet.org.br/vetindex/periodicos/revistado-instituto-adolfo-lutz/73-(2014)-4/primeiro-relato-desalmonella-enterica-e-campylobacter-spp-isolados-de/. Access on: 11 Ago. 2018. 
DIMITROV, K.; METCHEVA, R.; KENAROVA, A. Salmonella Presence - An Indicator of Direct and Indirect Human Impact on Gentoo in Antarctica. Biotechnology \& Biotechnological Equipment, Sofia, v.23, p.246-249, 2009. Supplementary 1. https://doi.org/10.1080/13102818.2009.10818411

DOBBIN, G.; HARIHARAN, H.; DAOUST, P.-Y.; HARIHARAN, S.; HEANEY, S.; COLES, M.; PRICE, L.; MUCKLE, C.A. Bacterial flora of free-living Double-crested cormorant (Phalacrocorax auritus) chicks on Prince Edward Island, Canada, with reference to enteric bacteria and antibiotic resistance. Comparative Immunology, Microbiology and Infectious Diseases, Lyon, v.28, n.1, p.71-82, 2005. https://doi.org/10.1016/SO147-9571(04)00059-1

DUARTE, E.L.; GUERRA, M.M.; BERNARDO, F.M. Salmonella and Listeria spp. carriage by gulls (larids). Revista Portuguesa de Ciências Veterinárias, Lisbon, v.97, n.544, p.181-187, 2002. Available from: http://www.fmv.ulisboa.pt/spcv/ edicao/12_2002/544_181_187.htm. Access on: 13 Jan. 2018.

EBERT, L.A.; SCHLEMPER, J.C.; PELISSER, M. R; PEREIRA, B. D. A; DA SILVA, M. A; BRANCO, J. O. Pathogenic Bacteria Associated with Kelp Gull Larus dominicanus (Charadriiformes, Laridae) on the Coast of Santa Catarina State-Brazil. International Journal of Current Microbiology and Applied Sciences, Tamilnadu, v.5, n.5, p.458-473, 2016. https://doi.org/10.20546/ijcmas.2016.505.048

EPSTEIN, J.H.; MCKEE, J.; SHAW, P.; HICKS, V.; MICALIZZI, G.; DASZAK, P.; KAUFMAN, G. The Australian White Ibis (Threskiornis molucca) as a Reservoir of Zoonotic and Livestock Pathogens. EcoHealth, New York, v.3, n.4, p.290-298, 2006. https://doi. org/10.1007/s10393-006-0064-2

FENLON, D.R. A comparison of Salmonella serotypes found in the faeces of gulls feeding at a sewage works with serotypes present in the sewage. Epidemiology $\odot$ Infection, Cambridge, v.91, n.1, p.47-52, 1983. https://doi.org/10.1017/ S0022172400060010

FENLON, D.R. Seagulls (Larus spp.) as vectors of salmonellae: an investigation into the range of serotypes and numbers of salmonellae in gull faeces. Epidemiology $\odot$ Infection, Cambridge, v.86, n.2, p.195-202, 1981. https://doi.org/10.1017/ S0O22172400068911

FERRAZZI, V.; GRILLI, G.; MORENO, M.A.; LELLI, D.; GALLAZZI, D. Health status of the hooded crow (Corvus corone cornix) in Northern Italy. In: Western Poultry Disease Conference. 2005. p. 111 .

FOTI, M.; RINALDO, D.; GUERCIO, A.; GIACOPELLO, C.; ALEO, A.; LEO, F.; FISICHELLA, V.; MAMMINA, C. Pathogenic microorganisms carried by migratory birds passing through the territory of the island of Ustica, Sicily (Italy). Avian Pathology, London, v.40, n.4, p.405-409, 2011 . https://doi.org/10.1080/0307945 7.2011 .588940

FREITAS, M.A.Q.; SANTOS, J.A.; PIRES, A.R.; NASCIMENTO, E. Infecção por Salmonella typhimurium de origem hídrica em garça gigante (Casmerodius albus egretta), em sua vida livre no Estado do Rio de Janeiro. Revista da Sociedade Brasileira de Medicina Tropical, Uberaba, v.11, n.5, p.161-166, 1977. https://doi. org/10.1590/SO037-86821977000500001
FRERE, E.; GANDINI, P.A.; PECK, R.M. Gaviota Cocinera (Larus dominicanus) como vector potencial de patógenos, em la costa patagónica. El Hornero, Buenos Aires, v15, n.02, p.93-97, 2000. Available from: https://ri.conicet.gov.ar/handle/1 1336/72054. Access on: 10 Jan. 2018.

FRICKER, C.R. A note on salmonella excretion in the black headed gull (Lams ribibundus) feeding at sewage treatment works. Journal of Applied Bacteriology, London, v.56, n.3, p.499-502, 1984. https://doi.org/10.1111/j.1365-2672.1984.tb01380.x

FUKUI, D. et al. Mass mortality of Eurasian tree sparrows (Passer montanus) from Salmonella Typhimurium DT40 in Japan, winter 2008-09. Journal of Wildlife Diseases, Lawrence, v.50, n.3, p.484-495, 2014. https://doi.org/10.7589/2012-12-321

GABRIEL, I.; MALLET, S.; SIBILLE, P. La microflore digestive des volailles: facteurs de variation et conséquences pour l'animal. INRAE Productions Animales, Saint-Genès-Champanelle, v.18, n.5, p.309-322, 2005. https://doi.org/10.20870/ productions-animales.2005.18.5.3535

GAST, R.K. Salmonella Infections. In: SAIF, Y.M. (ed). Diseases of Poultry. 12th. Ed. Ames: Blackwell, 2008. chap.16, p.619-665.

GIOVANNINI, S.; PEWSNER, M.; HÜSSY, D.; HÄCHLER, H.; DEGIORGIS, M.-P.R.; VON HIRSCHHEYDT, J.; ORIGGI, F.C. Epidemic of Salmonellosis in Passerine Birds in Switzerland With Spillover to Domestic Cats. Veterinary Pathology, Guelph, v.50, n.4, p.597606, 2013. https://doi.org/10.1177/0300985812465328

GIRDWOOD, R.W.A.; FRICKER, C.R.; MUNRO, D.; SHEDDEN, C.B.; MONAGHAN, P. The incidence and significance of salmonella carriage by gulls (Larus spp.) in Scotland. Epidemiology $\odot$ Infection, Cambridge, v.95, n.2, p.229-241, 1985. https://doi. org/10.1017/SO022172400062665

GRANT, D.; TODD, P.A.; PENNYCOTT, T. Monitoring wild greenfinch (Carduelis chloris) for Salmonella enterica typhimurium. Ecological Research, Kyoto, v.22, n.4, p.571-574, 2007. https://doi. org/10.1007/s1 1284-006-0056-2

HAESENDONCK, R.; RASSCHAERT, G.; MARTEL, A.; VERBRUGGHE, E.; HEYNDRICKX, M.; HAESEBROUCK, F.; PASMANS, F. Feral pigeons: A reservoir of zoonotic Salmonella Enteritidis strains? Veterinary Microbiology, Melbourne, v.195, p.101-103, 2016.

HAMER, S.A.; LEHRER, E.; MAGLE, S.B. Wild Birds as Sentinels for Multiple Zoonotic Pathogens Along an Urban to Rural Gradient in Greater Chicago, Illinois. Zoonoses and Public Health, Weinheim, v.59, n.5, p.355364, 2012.https://doi.org/10.1111/j.1863-2378.2012.01462.x

HARBOURNE, J.F. The Isolation of Salmonella Gallinarum in Wild Birds. Journal of Comparative Pathology and Therapeutics, Amsterdam, v.65, p.250-254, 1955. https://doi.org/10.1016/ S0368-1742(55)80023-9

HAUSER, E.; HUEHN, S.; JUNKER, E.; JABER, M.; SCHROETER, A.; HELMUTH, R.; RABSCH, W.; WINTERHOFF, N.; MALORNY, B. Characterisation of a phenotypic monophasic variant belonging to Salmonella enterica subsp. enterica serovar Typhimurium from wild birds and its possible transmission to cats and humans. Berliner und Munchener Tierarztliche Wochenschrift, Berlin, v.122, n.5-6, p.169-177, 2009. Available from: https://europepmc. org/article/med/19517930. Access on: 20 Feb. 2018. 
HERNÁNDEZ, J.; LINDBERG, P.; WALDENSTRÖM, J.; DROBNI, M.; OLSEN, B. A novel Salmonella serovar isolated from Peregrine Falcon (Falco peregrinus) nestlings in Sweden: Salmonella enterica enterica serovar Pajala (Salmonella Pajala). Infection Ecology $\diamond$ Epidemiology, Uppsala, v.2, n.1, p.7373, 2012. https://doi. org/10.3402/iee.v2i0.7373

HERNANDEZ S.M.; KEEL K.; SANCHEZ S.; TREES E.; GERNER-SMIDT P.; ADAMS J.K.; CHENG Y.; Ray A.; MARTIN G.; PRESOTTO A., RUDES M.G.; BROWN J.; BLEHERT D.S.; COTTRELL W.; MAURER J.J. Epidemiology of a Salmonella enterica subsp. enterica Serovar Typhimurium Strain Associated with a Songbird Outbreak. Applied and Environmental Microbiology, Bayreuth, v.78, n.20, p.7290-7298, 2012. https://doi.org/10.1128/AEM.01408-12

HERNANDEZ S.M.; WELCH C.N.; PETERS V.E.; LIPP E.K., CURRY S.; YABSLEY M.J.; SANCHEZ S.; PRESOTTO A., GERNER-SMIDT P.; HISE K.B.; HAMMOND E.; KISTLER W.M.; MADDEN M.; CONWAY A.L.; KWAN T.; MAURER J.J. Urbanized White Ibises (Eudocimus albus) as Carriers of Salmonella enterica of Significance to Public Health and Wildlife. PloS ONE, San Francisco, v.1 1, n.10, p.eO164402, 2016. https://doi.org/10.1371/journal.pone.0164402

HUBÁLEK, Z. An annotated checklist of pathogenic microorganisms associated with migratory birds. Journal of Wildlife Diseases, Lawrence, v.40, n.4, p.639-659, 2004. https://doi. org/10.7589/0090-3558-40.4.639

HUDSON, C.R.; QUIST, C.; LEE, M.D.; KEYES, K.; DODSON, S.V.; MORALES, C.; SANCHEZ, S.; WHITE, D.G.; MAURER, J.J. Genetic Relatedness of Salmonella Isolates from Nondomestic Birds in Southeastern United States. Journal of Clinical Microbiology, Washington, v.38, n.5, p.1860-1865, 2000. https://doi. org/10.1128/JCM.38.5.1860-1865.2000

HUGHES, L.A.; WIGLEY, P.; BENNETT, M.; CHANTREY, J.; WILLIAMS, N. Multi-locus sequence typing of Salmonella enterica serovar Typhimurium isolates from wild birds in northern England suggests host-adapted strain. Letters in Applied Microbiology, London, v.51, n.4, p.477-479, 2010. https:// doi.org/10.1111/j.1472-765X.2010.02918.x

IVESON, J.B.; SHELLAM, G.R.; BRADSHAW, S.D.; SMITH, D.W.; MACKENZIE, J.S.; MOFFLIN, R.G. Salmonella infections in Antarctic fauna and island populations of wildlife exposed to human activities in coastal areas of Australia. Epidemiology \& Infection, Cambridge, v.137, n.6, p.858-870, 2009.https://doi.org/10.1017/S0950268808001222

JIJÓN, S.; WETZEL, A.; LEJEUNE, J. Salmonella enterica isolated from wildlife at two Ohio rehabilitation centers. Journal of Zoo and Wildlife Medicine, Yulee, v.38, n.3, p.409-413, 2007. https://doi. org/10.1638/1042-7260(2007)38[409:SEIFWA]2.0.CO;2

JONES, D.N.; REYNOLDS, S.J. Feeding birds in our towns and cities: a global research opportunity. Journal of Avian Biology, Gotemburgo, v.39, n.3, p.265-271, 2008. https://doi. org/10.1111/j.0908-8857.2008.04271.x

JURADO-TARIFA, E.; TORRALBO, A.; BORGE, C.; CERDÀ-CUÉLLAR, M.; AYATS, T.; CARBONERO, A.; GARCÍA-BOCANEGRA, I. Genetic diversity and antimicrobial resistance of Campylobacter and Salmonella strains isolated from decoys and raptors. Comparative Immunology, Microbiology and Infectious Diseases, Lyon, v.48, p. 14-21, 2016. https://doi.org/10.1016/j.cimid.2016.07.003
KHIDHIR, Z.K. Isolation of Salmonella from Some Species of Wild Birds In Sulaimania. Al-Mustansiriyah Journal of Science, Baghdad, v.21, n.4, p.49-52, 2010. Available from: https://www.iasj. net/iasj?func $=$ article\&ald $=77528$. Access on: 18 May. 2018.

KIRK, J.H.; HOLMBERG, C.A.; JEFFREY, J.S. Prevalence of Salmonella spp in selected birds captured on California dairies. Journal of the American Veterinary Medical Association, Schaumburg, v.220, n.3, p.359-362, 2002. https://doi.org/10.2460/ javma.2002.220.359

KIRKPATRICK, C.E.; COLVIN, B.A. Salmonella spp. in nestling common barn-owls (Tyto alba) from southwestern New Jersey. Journal of Wildlife Diseases, Lawrence, v.22, n.3, p.340-343, 1986. https://doi.org/10.7589/0090-3558-22.3.340

KIRKPATRICK, C.E.; TREXLER-MYREN, V.P. A survey of free-living falconiform birds for Salmonella. Journal of the American Veterinary Medical Association, Schaumburg, v.189, n.9, p.997-998, 1986. Available from: https://pubmed.ncbi.nlm.nih.gov/3506002/. Access on: 13 May 2018.

KITADAI, N.; NINOMIYA, N.; MURASE, T.; OBI, T.; TAKASE, K. Salmonella Isolated from the Feces of Migrating Cranes at the Izumi Plain (2002-2008): Serotype, Antibiotic Sensitivity and PFGE Type. Journal of Veterinary Medical Science, Tokyo, v.72, n.7, p.939-942, 2010. https://doi.org/10.1292/jvms.09-0576

KLAASSEN, M.; HOYE, B.J.; NOLET, B.A.; BUTTEMER, W.A. Ecophysiology of avian migration in the face of current global hazards. Philosophical Transactions of the Royal Society B, London, v.367, n.1596, p.1719-1732, 2012. https://doi.org/10.1098/ rstb.2012.0008

KOCABIYIK, A.L.; CANGUL, I.T.; ALASONYALILAR, A.; DEDICOVA, D.; KARPISKOVA, R. Isolation of Salmonella Enteritidis Phage Type $21 \mathrm{~b}$ from a Eurasian Eagle-Owl (Bubo bubo). Journal of Wildlife Diseases, Lawrence, v.42, n.3, p.696-698, 2006. https://doi. org/10.7589/0090-3558-42.3.696

KRAWIEC, M.; KUCZKOWSKI, M.; KRUSZEWICZ, A.G.; WIELICZKO, A. Prevalence and genetic characteristics of Salmonella in free-living birds in Poland. BMC Veterinary Research, London, v.11, p.15, 2015. https://doi.org/10.1186/ s12917-015-0332-x

LA SALA, L.F.; PETRACCI, P.F.; RANDAZZO, V.; FERNÁNDEZMIYAKAWA, M.E. Enteric bacteria in Olrog's Gull (Larus atlanticus) and Kelp Gull (Larus dominicanus) from the Bahía Blanca Estuary, Argentina. El Hornero, Buenos Aires, v.28, n.2, p.59-64, 2013. Available from: http://www.scielo.org.ar/scielo.php?script=sci_ arttext\&pid=S0073-34072013000200002\&lng=es\&nrm= iso\&tlng=en. Access on: 1 Aug. 2018.

LADEAU, S.L.; KILPATRICK, A.M.; MARRA, P.P. West Nile virus emergence and large-scale declines of North American bird populations. Nature, London, v.447, n.7145, p.710-713, 2007. https://doi.org/10.1038/nature05829

LAWSON, B. et al. Epidemiological evidence that garden birds are a source of human salmonellosis in England and Wales. PloS ONE, San Francisco, v.9, n.2, p.e88968, 2014. https://doi. org/10.1371/journal.pone.0088968 
LÉVESQUE, B.; BROUSSEAU, P.; SIMARD, P.; DEWAILLY, E.; MEISELS, M.; RAMSAY, D.; JOLY, J. Impact of the Ring-Billed Gull (Larus delawarensis) on the Microbiological Quality of Recreational Water. Applied and Environmental Microbiology, Bayreuth, v.59, n.4, p.1228-1230, 1993. https://doi.org/10.1128/ AEM.59.4.1228-1230.1993

LIAKOPOULOS, A.; OLSEN, B.; GEURTS, Y.; ARTURSSON, K.; BERG, C.; MEVIUS, D.J.; BONNEDAHL, J. Molecular Characterization of Extended-Spectrum Cephalosporin-Resistant Enterobacteriaceae from Wild Birds (Kelp Gulls) in South America. Antimicrobial Agents and Chemotherapy, Washington, v.60, n.1 1, p.6924-6927, 2016. https://doi.org/10.1128/AAC.01120-16

LILLEHAUG, A.; JONASSEN, C.M.; BERGSJØ, B.; HOFSHAGEN, M.; THARALDSEN, J.; NESSE, L.L.; HANDELAND, K. Screening of Feral Pigeon (Colomba livia), Mallard (Anas platyrhynchos) and Graylag Goose (Anser anser) Populations for Campylobacter spp., Salmonella spp., Avian Influenza Virus and Avian Paramyxovirus. Acta Veterinaria Scandinavica, København, v.46, n.4, p. 193, 2005. https://doi.org/10.1186/1751-0147-46-193

LITERÁK, I.; ČÍŽEK, A.; HONZA, M. Examinations of Young Black-headed Gulls (Larus ridibundus) for the Detection of Salmonellae in the Environment. Acta Veterinaria Brno, Brno, v.61, n.2-3, p.141-146, 1992. https://doi.org/10.2754/ avb199261020141

LITERÁK, I.; VANKO, R.; DOLEJSKÁ, M.; ČÍŽEK, A.; KARPÍŠKOVÁ, R. Antibiotic resistant Escherichia coli and Salmonella in Russian rooks (Corvus frugilegus) wintering in the Czech Republic. Letters in Applied Microbiology, London, v.45, n.6, p.616-621, 2007. https://doi.org/10.1111/j.1472-765X.2007.02236.x

LÓPEZ-MARTÍN, J.; JUNOD, T.; RIQUELME, F.; CONTRERAS, C.; GONZÁLEZ-ACUÑA, D. Detection of Salmonella and Mycobacterium species in seagulls captured in Talcahuano, Chile. Revista Médica de Chile, Santiago, v.139, n.11, p.1496-1502, 2011. https:// doi.org/10.4067/S0034-98872011001100017

LU, J.; IDRIS, U.; HARMON, B.; HOFACRE, C.; MAURER, J.J.; LEE, M.D. Diversity and succession of the intestinal bacterial community of the maturing broiler chicken. Applied and Environmental Microbiology, Bayreuth, v.69, n.1 1, p.6816-6824, 2003. https:// doi.org/10.1 128/AEM.69.11.6816-6824.2003

MIKAELIAN, I.; DAIGNAULT, D.; DUVAL, M.C.; MARTINEAU, D. Salmonella infection in wild birds from Quebec. The Canadian Veterinary Journal, Guelph, v.38, n.6, p.385, 1997. Available from: https://www.ncbi.nlm.nih.gov/pmc/articles/PMC1576894/. Access on: 11 Aug. 2018.

MILLÁN, J.; ADURIZ, G.; MORENO, B.; JUSTE, R.A.; BARRAL, M. Salmonella isolates from wild birds and mammals in the Basque Country (Spain). Revue Scientifique et Technique, Paris, v.23, n.3, p.905-911, 2004. https://doi.org/10.20506/ rst.23.3.1529

MIRZAIE, S.; HASSANZADEH, M.; ASHRAFI, I. Identification and characterization of Salmonella isolates from captured house sparrows. Turkish Journal of Veterinary and Animal Sciences, Ankara, v.34, n.2, p.181-186, 2010. Available from: https:// journals.tubitak.gov.tr/veterinary/abstract.htm?id= 10827 . Access on: 21 Sep. 2018.
MOLINA-LOPEZ, R.A.; VALVERDÚ, N.; MARTIN, M.; MATEU, E.; OBON, E.; CERDÀ-CUÉLLAR, M.; DARWICH, L. Wild raptors as carriers of antimicrobial-resistant Salmonella and Campylobacter strains. Veterinary Record, London, v. 168, n.21, p.565, 2011. https://doi.org/10.1136/vr.c7123

MORENO, J.; BRIONES, V.; MERINO, S.; BALLESTEROS, C.; SANZ, J.J.; TOMÁS, G. Beneficial effects of cloacal bacteria on growth and fledging size in nestling pied flycatchers (Ficedula hypoleuca) in Spain. The Auk, Oxford, v.120, n.3, p.784-790, 2003. https:// doi.org/10.2307/4090108

MURRAY, C.J. Salmonellae in the environment. Revue Scientifique et Technique, Paris, v.10, n.3, p.765-785, 1991. https://doi. org/10.20506/rst.10.3.568

NEEL, R.; MINOR, L.; KAWEH, M. Une nouvelle espèce de Salmonella isolee chez un corbeau (Corvus-corax):-s-Hessarek. Annales de l'Institut Pasteur, Paris, p.271-274, 1953. Available from: https://archrazi.areeo.ac.ir/article_108386.html. Access on: 10 Apr. 2018.

OLSEN, B.; BERGSTRÖM, S.; MCCAFFERTY, D.J.; SELLIN, M.; WISTRÖM, J. Salmonella enteritidis in Antarctica: zoonosis in man or humanosis in penguins? The Lancet, London, v.348, n.9037, p.1319-1320, 1996. https://doi.org/10.1016/ S0140-6736(05)65807-2

PALMGREN, H.; ASPÁN, A.; BROMAN, T.; BENGTSSON, K.; BLOMQUIST, L.; BERGSTRÖM, S.; SELLIN, M.; WOLLIN, R.; OLSEN, B. Salmonella in Black-headed gulls (Larus ridibundus); prevalence, genotypes and influence on Salmonella epidemiology. Epidemiology (2) Infection, Cambridge, v.134, n.3, p.635-644, 2005. https:// doi.org/10.1017/S0950268805005261

PALMGREN, H.; MCCAFFERTY, D.; ASPÁN, A.; BROMAN, T.; SELLIN, M.; WOLLIN, R.; BERGSTRÖM, S.; OLSEN, B. Salmonella in subAntarctica: low heterogeneity in Salmonella serotypes in South Georgian seals and birds. Epidemiology \& Infection, Cambridge, v.125, n.2, p.257-262, 2000. https://doi.org/10.1017/ S0950268899004586

PALMGREN, H.; SELLIN, M.; BERGSTRÖM, S.; OLSEN, B. Enteropathogenic Bacteria in Migrating Birds Arriving in Sweden. Scandinavian Journal of Infectious Diseases, Umeå, v.29, n.6, p.565568, 1997. https://doi.org/10.3109/00365549709035895

PALOMO, G. et al. Dissemination of Antimicrobial-Resistant Clones of Salmonella enterica Among Domestic Animals, Wild Animals, and Humans. Foodborne Pathogens and Disease, Knoxville, v. 10, n.2, p.171-176, 2013. https://doi.org/10.1089/fpd.2012.1288

PEDERSEN, K.; MARKS, D.R.; ARSNOE, D.M.; AFONSO, C.L.; BEVINS, S.N.; MILLER, P.J.; RANDALL, A.R.; DELIBERTO, T.J. Avian Paramyxovirus Serotype 1 (Newcastle Disease Virus), Avian Influenza Virus, and Salmonella spp. in Mute Swans (Cygnus olor) in the Great Lakes Region and Atlantic Coast of the United States. Avian Diseases, Jacksonville, v.58, n. 1, p.129-136, 2013. https://doi.org/10.1637/10638-081413-Reg.1

PENFOLD, J.B.; AMERY, H.C.C.; PEET, P.J.M. News and Notes: Gastroenteritis associated with wild birds in a hospital kitchen. British Medical Journal, London, v.2, n.6193, 801-803, 1979. https://doi.org/10.1136/bmj.2.6193.801 
PENNYCOTT, T.W.; PARK, A.; MATHER, H.A. Isolation of different serovars of Salmonella enterica from wild birds in Great Britain between 1995 and 2003. Veterinary Record, London, v.158, n.24, 817-820, 2006. https://doi.org/10.1136/ vr.158.24.817

PENNYCOTT, T.W.; MATHER, H.A.; BENNETT, G.; FOSTER, G. Salmonellosis in garden birds in Scotland, 1995 to 2008: geographic region, Salmonella enterica phage type and bird species. Veterinary Record, London, v.166, n.14, p.419-421, 2010. https://doi.org/10.1136/vr.b4761

PHALEN, D.N.; DREW, M.L.; SIMPSON, B.; ROSET, K.; DUBOSE, K.; MORA, M. Salmonella enterica subsp. Enterica in Cattle Egret (Bubulcus ibis) chicks from central Texas: prevalence, serotypes, pathogenicity, and epizootic potential. Journal of Wildlife Diseases, Lawrence, v.46, n.2, p.379-389, 2010. https:// doi.org/10.7589/0090-3558-46.2.379

PLANT, C.W. Salmonellosis in wild birds feeding at sewage treatment works. Epidemiology \& Infection, Cambridge, v.81, n. 1, p.43-48, 1978. https://doi.org/10.1017/S0022172400053754

QUESSY, S.; MESSIER, S. Prevalence of Salmonella spp., Campylobacter spp. and Listeria spp. in ring-billed gulls (Larus delawarensis). Journal of Wildlife Diseases, Lawrence, v.28, n.4, p.526-531, 1992. https://doi.org/10.7589/0090-3558-28.4.526

RADWAN, A.I.; LAMPKY, J.R. Enterobacteriaceae isolated from cowbirds (Molothrus ater) and other species of wild birds in Michigan. Avian Diseases, Jacksonville, v.16, n.2, p.343-350, 1972. https://doi.org/10.2307/1588799

RECHE, M.P.; JIMÉNEZ, P.A.; ALVAREZ, F.; RÍOS, J.E.G.; ROJAS, A.M.; PEDRO, P. Incidence of Salmonellae in Captive and Wild Free-Living Raptorial Birds in Central Spain. Journal of Veterinary Medicine, Series B, Weinheim, v.50, n. 1, p.42-44, 2003. https:// doi.org/10.1046/j.1439-0450.2003.00623.x

REFSUM, T.; HANDELAND, K.; BAGGESEN, D.L.; HOLSTAD, G.; KAPPERUD, G. Salmonellae in Avian Wildlife in Norway from 1969 to 2000. Applied and Environmental Microbiology, Bayreuth, v.68, n. 11 , p.5595-5599, 2002. https://doi.org/10.1128/ AEM.68.11.5595-5599.2002

REFSUM, T.; VIKøREN, T.; HANDELAND, K.; KAPPERUD, G.; HOLSTAD, G. Epidemiologic and pathologic aspects of Salmonella Typhimurium infection in passerine birds in Norway. Journal of Wildlife Diseases, Lawrence, v.39, n.1, p.64-72, 2003. https:// doi.org/10.7589/0090-3558-39.1.64

RETTGER, L.F. Further studies on fatal septicemia in young chickens, or "white diarrhea". The Journal of Medical Research, Boston, v.21, n.1, p.115-123, 1909. Available from: https:// www.ncbi.nlm.nih.gov/pmc/articles/PMC2098883/. Access on: 21 Sep. 2018.

ROUFFAER, L.O.; LENS, L.; HAESENDONCK, R.; TEYSSIER, A.; HUDIN, N.S.; STRUBBE, D.; HAESEBROUCK, F.; MARTEL, A. House Sparrows Do Not Constitute a Significant Salmonella Typhimurium Reservoir across Urban Gradients in Flanders, Belgium. PloS ONE, San Francisco, v. 1 1, n.5, p.e0155366, 2016. https://doi. org/10.1371/journal.pone.0155366
SKOV, M.N.; MADSEN, J.J.; RAHBEK, C.; LODAL, J.; JESPERSEN, J.B.; JØRGENSEN, J.C.; DIETZ,H.H.; CHRIÉL, M.;BAGGESEN, D.L Transmission of Salmonella between wildlife and meat-production animals in Denmark. Journal of Applied Microbiology, London, v.105, n.5, p. 1558-1568, 2008. https://doi.org/10.1111/j.1365-2672.2008.03914.x

SMITH, W.A.; MAZET, J.A.K.; HIRSH, D.C. Salmonella in California wildlife species: prevalence in rehabilitation centers and characterization of isolates. Journal of Zoo and Wildlife Medicine, Yulee, v.33, n.3, p.228-235, 2002. https://doi. org/10.1638/1042-7260(2002)033[0228:SICWSP]2.0.CO;2

SOUSA, E.; BERCHIERI JÚNIOR, A.; PINTO, A.A.; MACHADO, R.Z.; CARRASCO, A.O.T.; MARCIANO, J.A.; WERTHER, K. Prevalence of Salmonella spp. Antibodies to Toxoplasma gondii, and Newcastle Disease Virus in Feral Pigeons (Columba livia) in the city of Jaboticabal, Brazil. Journal of Zoo and Wildlife Medicine, Yulee, v.41, n.4, p.603-607, 2010b. https://doi.org/10.1638/2008-0166.1

SOUSA, E.; WERTHER, K.; BERCHIERI JÚNIOR, A. Assessment of Newcastle and infectious bronchitis pathogens, and Salmonella spp. in wild birds captured near poultry facilities. Arquivo Brasileiro de Medicina Veterinária e Zootecnia, Belo Horizonte, v.62, n.1, p.219-223, 2010a. https://doi.org/10.1590/SO102-09352010000100031

SPECKMANN, G. Investigation on the occurrence of salmonellae in mute swans (Cygnus olor). The Canadian Veterinary Journal, Guelph, v.16, n.6, p.174-175, 1975. Available from: https://www.ncbi.nlm. nih.gov/pmc/articles/PMC1696928/. Access on: 12 Oct. 2018.

SULZNER, K.; KELLY, T.; SMITH, W.; JOHNSON, C.K. Enteric pathogens and antimicrobial resistance in turkey vultures (Cathartes Aura) feeding at the wildlife-livestock interface. Journal of Zoo and Wildlife Medicine, Yulee, v.45, n.4, p.93 1-934, 2014. https:// doi.org/10.1638/2012-0217.1

TANAKA, C.; MIYAZAWA, T.; WATARAI, M.; ISHIGURO, N. Bacteriological Survey of Feces from Feral Pigeons in Japan. Journal of Veterinary Medical Science, Tokyo, v.67, n.9, p.951-953, 2005. https://doi.org/10.1292/jvms.67.951

TAUNI, M.A.; ÖSTERLUND, A. Outbreak of Salmonella typhimurium in cats and humans associated with infection in wild birds. Journal of Small Animal Practice, Quedgeley, v.41, n.8, p.339-341, 2000. https://doi.org/10.1111/j.1748-5827.2000.tb03214.x

TIZARD, I. Salmonellosis in wild birds. Seminars in Avian and Exotic Pet Medicine, Philadelphia, v.13, n.2, p.50-66, 2004. https:// doi.org/10.1053/j.saep.2004.01.008

UNE, Y.; SANBE, A.; SUZUKI, S.; NIWA, T.; KAWAKAMI, K.; KUROSAWA, R.; IZUMIYA, H.; WATANABE, H.; KATO, Y. Salmonella enterica Serotype Typhimurium Infection Causing Mortality in Eurasian Tree Sparrows (Passer montanus) in Hokkaido. Japanese Journal of Infectious Diseases, Shinjuku, v.61, n.2, p.166-167, 2008. Available from: https://www.niid.go.jp/niid/images/ JJID/61/166.pdf. Access on: 24 Jun. 2018.

VAN ANDEL, M.; JACKSON, B.H.; MIDWINTER, A.C.; ALLEY, M.R.; EWEN, J.G.; MCINNES, K.; HOFF, R.J.; REYNOLDS, A.D.; FRENCH, N. Investigation of mortalities associated with Salmonella spp. infection in wildlife on Tiritiri Matangi Island in the Hauraki Gulf of New Zealand. New Zealand Veterinary Journal, Wellington, v.63, n.4, p.235-239, 2015. https://doi.org/10.1080/00480169.2014.990065 
VELARDE, R.; PORRERO, M.C.; SERRANO, E.; MARCO, I.; GARCÍA, M.; TÉLLEZ, S.; DOMÍNGUEZ, L.; AYMI, R.; LAVÍN, S. Septicemic salmonellosis caused by Salmonella Hessarek in wintering and migrating Song Thrushes (Turdus philomelos) in Spain. Journal of Wildlife Diseases, Lawrence, v.48, n.1, p.113-121, 2012. https://doi.org/10.7589/0090-3558-48.1.113

VICO, J.P.; MAINAR-JAIME, R.C. Salmonellosis in wild birds and its relationship with the infection in finishing pigs. In: 87 th International Conference on the Epidemiology and Control of Biological, Chemical and Physical Hazards in Pigs and Pork. Anais... Ames: lowa State University Digital Press, 2011 . p.264-267. https://doi.org/10.31274/ safepork-180809-639
VIGO, G.B.; LEOTTA, G.A.; CAFFER, M.I.; SALVE, A.; BINSZTEIN, N.; PICHEL, M. Isolation and characterization of Salmonella enterica from Antarctic wildlife. Polar Biology, Bremerhaven, v.34, n.5, p.675-681, 2011. https://doi.org/10.1007/s00300-010-0923-8

VLAHOVIĆ, K.; MATICA, B.; BATA, I.; PAVLAK, M.; PAVIČIĆ, Ž.; POPOVIĆ, M.; NEJEDLI, S.; DOVČ, A. Campylobacter, Salmonella and Chlamydia in free-living birds of Croatia. European Journal of Wildlife Research, Ciudad Real, v.50, n.3, p.127-132, 2004. https://doi.org/10.1007/s10344-004-0052-1

WINFIELD, M.D.; GROISMAN, E.A. Role of Nonhost Environments in the Lifestyles of Salmonella and Escherichia coli. Applied and Environmental Microbiology, Bayreuth, v.69, n.7, p.3687-3694, 2003. https://doi.org/10.1 128/AEM.69.7.3687-3694.2003 